\title{
Update from RCP Quality Improvement: QI, what do we need to learn?
}

Quality improvement activities are now an established part of the training of postgraduate doctors in the UK, largely by being involved with or leading quality improvement projects. Learning activities should enable the development of professional capabilities that are outlined by the General Medical Council (GMC). ${ }^{1}$ However, the more detailed knowledge, skills and practice that need to be learned through this had not been clearly described. It is now widely accepted that quality improvement includes both technical and behavioural elements, and that learning these through practical experience as well as source materials is necessary.

The Academy of Medical Royal Colleges (AoMRC) report Quality Improvement - training for better outcomes published in 2016 started to outline knowledge, skills, values and behaviours that would be required within a quality improvement curriculum at different stages of medical careers and recommended that royal colleges should develop these further. ${ }^{2}$ Work over the last 2 years has continued, with the medical royal colleges quality improvement leads working together through the AoMRC to describe six capabilities that should be developed through training activities. ${ }^{3}$ They have also recommended how these might be assessed for postgraduate doctors.

The six capabilities are:

$>$ understanding the system

$>$ human elements of change

$>$ measurement of change

$>$ implementing change

$>$ sustainability and spread

$>$ leadership and team-working.

More detailed descriptions of each capability are given in the report, together with illustrative professional activities that should demonstrate this learning; the relationship of each to the GMC's professional capabilities is also shown.

Assessment drives learning, and therefore how these capabilities are assessed is recommended. The key elements that need to be assessed are personal qualities, working within teams, articulating the need for improvement, and patient and carer involvement. Learning will be demonstrated largely by showing the use of improvement techniques through a reflective portfolio evidence of involvement and leadership of quality improvement projects. However, these should also be captured through 360-degree feedback, direct observation of practical use of techniques as non-clinical skills, supervisor reports and case-based discussions. Royal colleges should also consider how quality improvement knowledge and skills can be demonstrated through professional examinations and these are already in place or developing in some specialties.
Training and assessing learning and competencies in a relatively new professional discipline will have significant challenges over the next few years. While more and more established physicians and other healthcare professionals are becoming conversant with quality improvement practice and competencies, the numbers remain relatively small compared to the demand for assessment that will be required. Arguably, this may be more developed in some areas of the UK than others. Much of the expertise in quality improvement within trusts, boards and educational bodies lies in non-medical professionals. At a time when multiprofessional learning is being championed, and given that quality improvement is a multiprofessional activity, this seems an opportunity for professionals across disciplines to be actively involved in assessing doctors in training. Trusts and boards that have more developed training of staff in quality improvement will largely do this in multiprofessional groups and medical education leads need to be flexible to maximise this opportunity for doctors in training. For trainees working in organisations with less support available, it is imperative that this support is available at a programme level, and that professional organisations, educational bodies and the wider NHS support and guide local employers to develop support and training and activities.

The quality improvement curriculum as explained in the AoMRC report is of course applicable to other healthcare staff, both clinical and non-clinical. It has been shared with other quality improvement experts in the NHS and has been well received as a generic approach that could be adopted across the NHS. As with all areas of knowledge the field of quality improvement will continue to develop and therefore the details of both the curriculum and the learning activities will need to adapt. While the curriculum is aimed at doctors in training, it gives a framework for career long learning in quality improvement

As quality improvement in healthcare is still a relatively young discipline with expertise in a minority of staff, the challenge of developing large numbers of staff is significant. It is, however, an expectation within the NHS in England ${ }^{4}$ and in the devolved nations that regulators will be monitoring. ${ }^{5}$

Within the Royal College of Physicians (RCP), RCP Quality Improvement (QI) and Education teams will be working with this curriculum to develop support and direct training of trainees, assessors, established consultants and other healthcare professions in quality improvement. An early example of this is the e-learning module for educational supervisors to help them support trainees participating in quality improvement projects and programmes. ${ }^{6}$ Our RCPQI faculty of experts will be supported in continuing to develop their expertise, and we expect their number to continue to grow. They will also be available to support trainers and trainees. 
Dr John Dean Clinical director of quality improvement and patient safety, Royal College of Physicians

Dr Emma Vaux

Senior censor and vice president (education and training), Royal College of Physicians

\section{References}

1 General Medical Council. Generic professional capabilities framework. Manchester: GMC, 2017.

2 Academy of Medical Royal Colleges. Quality Improvement - training for better outcomes. London: AoMRC, 2016.
3 Academy of Medical Royal Colleges. AoMRC Quality Improvement training for better outcomes. Developing Quality Improvement Practice. London: AoMRC, (in press).

4 NHS Improvement. Embedding quality improvement skills. NHS, 2017. https://improvement.nhs.uk/resources/embedding-qualityimprovement-skills [Accessed 02 May 2019].

5 Care Quality Commission. Quality improvement in hospital trusts: Sharing learning from trusts on a journey of QI. Newcastle upon Tyne: CQC, 2018

6 Royal College of Physicians. Supervising quality improvement projects: A guide for supervisors. London: RCP. https://rcplondon.learnupon. com/store/413012-supervising-quality-improvement-project [Accessed 02 May 2019].

\section{A guide for supervisors}

Supervising quality improvement projects

This online resource has been developed by the Royal College of Physicians (RCP) to help clinicians from any specialty to identify learning opportunities relating to quality improvement, to support and guide their trainees throughout their quality improvement projects.

For more information, please email: elearning@rcplondon.ac.uk

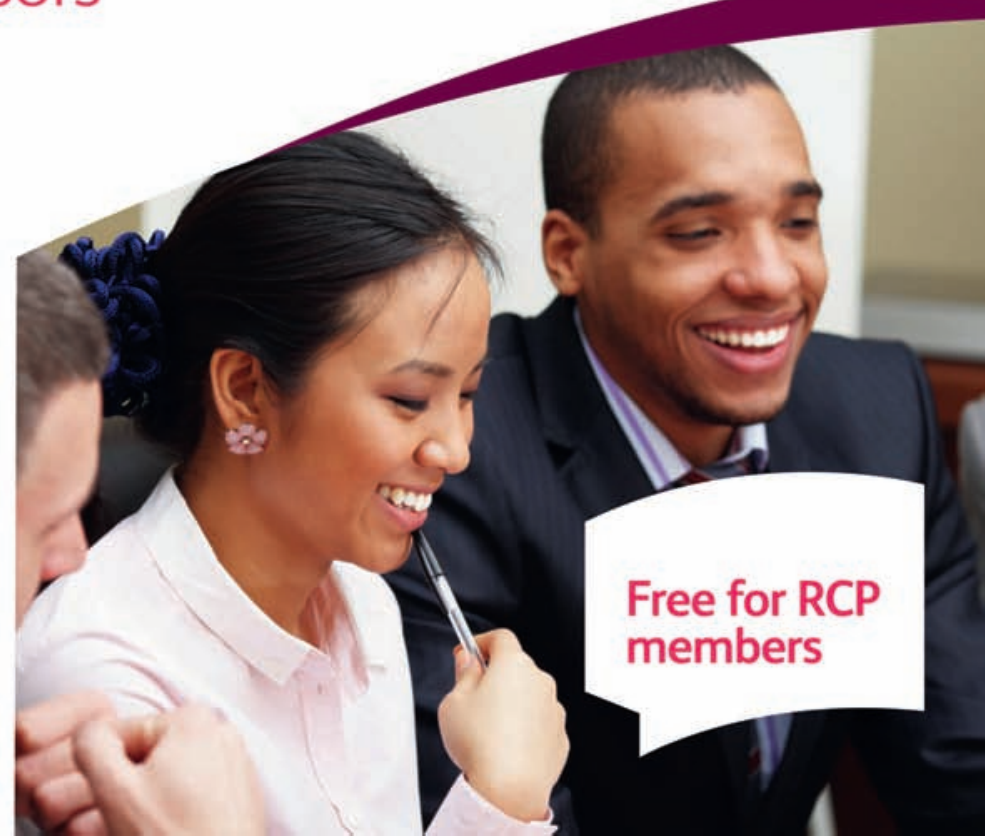

